\title{
Linking Information Exchange to Planning and Control: An Overview
}

\author{
Kasper Kiil ${ }^{1}$, Heidi C. Dreyer ${ }^{1}$ and Hans-Henrik Hvolby ${ }^{1,2}$ \\ ${ }^{1}$ Norwegian University of Science and Technology, Department of Production and Quality \\ Engineering, S.P. Andersens veg 5, 7491 Trondheim, Norway \\ ${ }^{2}$ Aalborg University, Department of Production, Fibigerstraede 16, 9220 Aalborg, Demark \\ kasper.kill@ntnu.no, heidi.c.dreyer@ntnu.no, hhh@celog.dk
}

\begin{abstract}
This paper creates an overview of previous research which has been conducted related to how information exchange can improve planning and control decisions in order to establish directions for future research. By synthetizing literature reviews, more than 130 unique papers are considered in the analysis. It is identified that most research only examines a dyad relation, and there exist a strong focus on how to improve the order replenishment by using demand and inventory level information. Case studies, simulation models, and inclusion of more complex network structures is suggested for future research.
\end{abstract}

Keywords: Information exchange, Planning and control, Future research

\section{Introduction}

The constant search for cost reductions and efficiency gains without compromising other performances measures creates an enormous pressure on planning along the supply chain. Exchanging information, e.g. inventory levels, customer demand, forecast, among supply chain partners for improving planning and control decisions has been emphasized as an effective mean to improve performance [4] [14] [15]. Some of the cited benefits includes e.g. reduction of bull-whip effect, better and faster response to customer, greater visibility, reduced inventories, and increased service level [2] [11] [13]. Exchanging information has even been recognized as the core of collaborative supply chain management [13] [16]. However, there exist no overview of the many small conclusions which have been made [7] [16] [17] and this lacking overview complicates the process of trying to understand how information exchange influences planning and control decisions [12].

This study starts the journey of linking information exchange to planning and control by establishing the necessary overview through examining and synthesizing previous literature reviews. The objective of the study is to answer what research there previously has been conducting related to information exchange and planning and control in order to establish areas of future research. 


\section{Background}

Information Exchange. Information sharing and information exchange appear to be used interchangeably and they both refer to the extent to which operational, tactical or strategic information is available between supply chain members [16] [19]. Information exchange has been studied for decades and its impact on supply chain performance can be traced back to the work of Forrester [6] where the bull-whip effect was first conceived. Causes and recommendations to counteract it has been widely discussed and joint solutions as collaborative planning, replenishment and forecasting (CPRF) has been proposed as well (see e.g. [14] [5]). Today, it is well established that increased information exchange can lead to higher supply chain performance [15] [20]. Even though, it is well-understood that it can lead to higher performance, the road of how to get there is still blurred: "Despite the progress, the research underscored the fact that many SC managers do not fully understand the nature and role of an informationsharing capability. Thus, a proven, well-traveled path with well-defined signposts to the development of this important SC capability has not yet been established" [3, p. 241].

Design of Planning and Control. Assuming information is exchanged with supply chain partners a vast amount of literature investigates how it may be utilized [7] [8]. The application is usually through improved planning and control decisions, i.e. how much to order, when to order, routing decisions, inventory allocations, safety stock etc. [9]. [10] [18] have explained how planning and control, and its underlying decisions, should be designed in accordance with 1) market requirements, 2) product characteristics and 3) process type. However, information exchange is not included as a basis for how planning decisions should be designed. Even though, numerous studies explicitly focus at how those two are connected and how planning and control decisions can be designed (and improved) if specific information is available. Other authors have previously emphasized this concern: "no studies have addressed aspects related to information sharing as a determinant of planning approach." [12, p. 148]. Essentially, there exist no encapsulating framework, or well-traveled path [3], to understand how information exchange influences planning and control decisions, nevertheless the field has still received many valuable but separate contributions [19].

Linking Information Exchange to Planning and Control. Previously, the type of information exchanged has been grouped into 20 categories ranging from demand information to what type of forecasting model or time fence settings the different supply chain partners apply [8]. Planning and control decisions has been divided into eight categories with facility location as the most strategic and order replenishment and shipment decision as the most operational [8]. The purpose of this paper is to connect these two dimensions, and the underlying categories, by generating an overview of which type of information (exchanged between supply chain partners) there previously has been examined to improve planning and control decisions. Secondly, it should be considered how this research has been conducted. The applied method (analytical, simulation, etc.) and the supply chain structure (dyad, divergent, etc.) condenses the most important parts of how the research has been conducted, and has also been used in previous review papers [7] [17]. 


\section{Research Design}

To grasp the tremendous amount of available literature on information exchange and planning and control literature reviews can provide valuable information. The initial literature search for this study discovered several literature reviews, but none of them directly linked information exchange to planning and control decisions. Therefore, this study assembles previous review papers to create this link and overview. The research process can be divided into two main steps:

Step 1: Locating Studies. First, only published academic articles and proceedings was chosen to be included. Second, to not only rely on a single database four databases (Scopus, ScienceDirect, Google Scholar, and Emerald) were selected. Third, keywords like information exchange, information sharing and collaboration was combined with supply chain at all four databases. Fourth, to reduce the number of articles and ensure a relative novel result a 15-year time period spanning from (including) 2000 to 2014 was selected. 32 papers was identified in this at this stage, this is predominantly because only review papers, and potential review papers, were selected for further evaluation.

Step 2: Selection and Evaluation. A comprehensive review [8] presents a conceptual framework of seven dimensions in order to categorize this type of literature. This framework was later applied in a simplified version with four dimensions [17]. Those four dimensions correspond to what has been discussed in the beginning of this paper and are conveyed in this paper. The first two considers what type of information and which planning and control decisions. The last two is concerned with how the research was conducted:
1. Type of information exchanged
3. Applied method
2. Type of planning decision
4. Supply chain structure

The 32 review papers from the step 1 were read more in detail and only review papers which had specified those four dimensions (for the papers they reviewed) was selected for further analysis. As an example, the review by Giard and Sali (2013) [7] was excluded as they did only specify the planning decision as being either operational, tactical, or strategic which were considered too coarse. Six review papers from the period between 2000 and 2014 was identified to fulfill the selection criteria [1] [8] [13] [17] [19] [21]. Within the six review papers, a total of 176 papers and 131 unique papers had been reviewed.

As the previous review papers provide the main data for the subsequent analysis, their selection process specifies what papers there ultimately are included. The most common keywords used within the six selected review papers includes, supply chain information sharing, flow coordination, supply chain dynamics and collaboration. Some of them have applied a rather broad search approach in operation management related journals [19] [8] other focus explicitly on modeling papers [1], and some solely on two stage supply chain structures [17]. It should be noted that the chosen method, of only using review papers as the main data source, do not guarantee that all relevant (unique) papers are identified and included, however the method is still highly suitable to indicate previous trends. 


\section{$4 \quad$ Analysis and Discussion}

Haung et al., (2003) [8] present 20 different categories of which type of information to exchange, and eight categories of different planning and control decisions. The 131 unique papers has been classified according to those categories and are presented in Table 1.

Table 1. Number of papers examine the relation between information exchange and planning and control decisions [1] [8] [13] [17] [19] [21].

\section{PLANNING AND CONTROL DECISION}

\begin{tabular}{|c|c|c|c|c|c|c|c|c|c|c|c|}
\hline & & 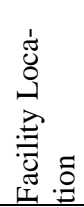 & $\begin{array}{l}\text { Do } \\
\text { : } \\
0 \\
0 \\
0 \\
0 \\
0 \\
0\end{array}$ & 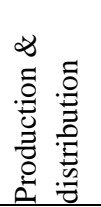 & 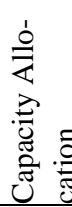 & 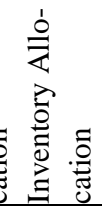 & 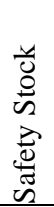 & 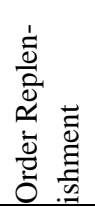 & 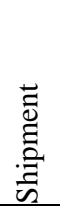 & $\begin{array}{l}\vec{D} \\
:=0 \\
0 \\
0 \\
0 \\
0 \\
0 \\
z\end{array}$ & $\underset{\Xi}{\Xi}$ \\
\hline \multirow{22}{*}{ 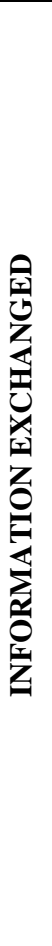 } & Demand forecast & 0 & 0 & 3 & 1 & 3 & 1 & 7 & 1 & 2 & 18 \\
\hline & Production schedule & 0 & 0 & 4 & 0 & 0 & 0 & 3 & 1 & 0 & 8 \\
\hline & Forecasting model & 0 & 0 & 0 & 0 & 1 & 0 & 0 & 0 & 0 & 1 \\
\hline & Time fence & 0 & 0 & 1 & 0 & 0 & 0 & 0 & 0 & 0 & 1 \\
\hline & Inventory level & 0 & 0 & 1 & 1 & 6 & 3 & 21 & 5 & 3 & 40 \\
\hline & Backlog cost & 0 & 0 & 0 & 0 & 0 & 0 & 1 & 0 & 0 & 1 \\
\hline & Holding cost & 0 & 0 & 0 & 0 & 0 & 0 & 3 & 0 & 0 & 3 \\
\hline & Service level & 0 & 0 & 0 & 0 & 1 & 0 & 0 & 0 & 1 & 2 \\
\hline & Capacity & 2 & 4 & 3 & 0 & 0 & 0 & 6 & 1 & 1 & 17 \\
\hline & Manufacturing leadtime & 0 & 0 & 0 & 0 & 1 & 0 & 3 & 0 & 1 & 5 \\
\hline & Cost of process & 2 & 3 & 3 & 0 & 0 & 0 & 1 & 0 & 0 & 9 \\
\hline & Quality & 0 & 0 & 0 & 0 & 0 & 0 & 1 & 0 & 1 & 2 \\
\hline & Delivery & 0 & 0 & 1 & 0 & 0 & 0 & 3 & 3 & 1 & 8 \\
\hline & Delivery lead time & 0 & 0 & 0 & 0 & 0 & 0 & 2 & 0 & 0 & 2 \\
\hline & Variation of lead time & 0 & 0 & 1 & 0 & 0 & 0 & 1 & 1 & 3 & 6 \\
\hline & Demand (e.g. POS) & 0 & 1 & 4 & 2 & 2 & 0 & 41 & 3 & 11 & 64 \\
\hline & Demand variability & 0 & 0 & 0 & 1 & 0 & 0 & 6 & 0 & 3 & 10 \\
\hline & Batch size & 0 & 0 & 2 & 0 & 0 & 0 & 5 & 1 & 0 & 8 \\
\hline & Demand correlation & 0 & 0 & 0 & 0 & 0 & 0 & 3 & 0 & 0 & 3 \\
\hline & Delivery due date & 0 & 0 & 1 & 0 & 0 & 0 & 1 & 1 & 0 & 3 \\
\hline & Not specified & 0 & 0 & 1 & 0 & 2 & 0 & 6 & 0 & 8 & 17 \\
\hline & Sum & 4 & 8 & 25 & 5 & 16 & 4 & 114 & 17 & 35 & 228 \\
\hline
\end{tabular}

Table 1 specifies that e.g. seven unique papers has investigated the exchange of demand forecast in order to make better decisions related to order replenishment. If a paper has investigated how exchange of demand forecast could be used to improve both inventory allocation and order replenishment a full point has been assigned to both inventory allocation and order replenishment. 
Clearly, the first comment from Table 1 is that sharing demand information (i.e. sharing downstream demand, especially by the end customer, with upstream facilities), in order to improve order replenishment (i.e. how a business entity places an order) is the single most investigated relation between information exchange and planning and control decisions. Out of the 131 unique papers almost one-third had this particular relation included. The exchange of inventory levels and demand forecast, to improve decisions related to order replenishment, has also received a great amount of attention.

Planning and Control Decision. Of the eight different planning decisions, order replenishment has been considered in almost all papers; remarkably 114 papers includes this decision. Production and distribution planning is considered in 25 papers while 17 papers investigates shipments (i.e. shipment within the same tier or emergency shipments where one tier is exclude [8]). Surprisingly, decisions related to inventory allocation, safety stock, or capacity allocation has only received very little attention from previous literature. It is surprising as it would be expected that sharing customers forecast or point-of-sales data could improve the focal company's own forecast and hereby obtain lower safety stock levels. Also, if a complete chain is examined, the total inventory level could might be reduced if it is allocated according to where the demand is expected.

Exchange of Information. Of the 20 different kinds of information possible to exchange demand, inventory level, and demand forecast are the top three followed by capacity and demand variability as forth and fifth. With demand, demand forecast, and demand variability included in top five a tendency of how downstream information, compared to upstream information, can be utilized is indeed present [1]. It could be expected that sharing upstream inventory levels and variability in delivery time may provide confidence further down the supply chain and could help decrease inventory levels. Also, even though the shelf life, or age of inventory, is not included in Table 1 it has been showed how it can improve performance [4].

Supply Chain Structure. To fully understand the research, which previously has been conducted related to information exchange and planning and control, Table 2 presents how it has been conducted by comparing the applied method and the supply chain structure from the 131 unique papers. From the table it can be concluded that nearly half of the papers studies a dyadic structure. Dyadic being the most common supply chain structure followed by serial and divergent which have been in examine in respectively 24 and 23 papers. On the other hand, less than $7 \%$ of the papers adopts the more comprehensive network perspective. [8] explains that dyadic structure is too simple to be compared with real supply chains and some of the implications should only be applied on a conceptual level. However, only involving two entities keeps the complexity down and makes it possible to apply an analytical (i.e. calculus and probability) method [19], which may also explain the high occurrence of the analytical method combined with the dyadic structure.

Applied Method. With the high concentration of analytical method and dyadic structure the analytical method is the most common applied method overall. Simulation methods like discrete event simulation and agent based simulation are used across most supply chain structures, while systems dynamic mostly have been applied in serial supply chain structures. Interestingly, no case studies have been included which, besides 
simulation, appear as a suitable method if a complete supply chain network should be examined. Using the case study approach may also provide new ideas for what type of information to share, and offer examples of what are most common and beneficial to share.

Table 2. Applied method and supply chain structures in the reviewed papers from Table 1 [1] [8] [13] [17] [19] [21].

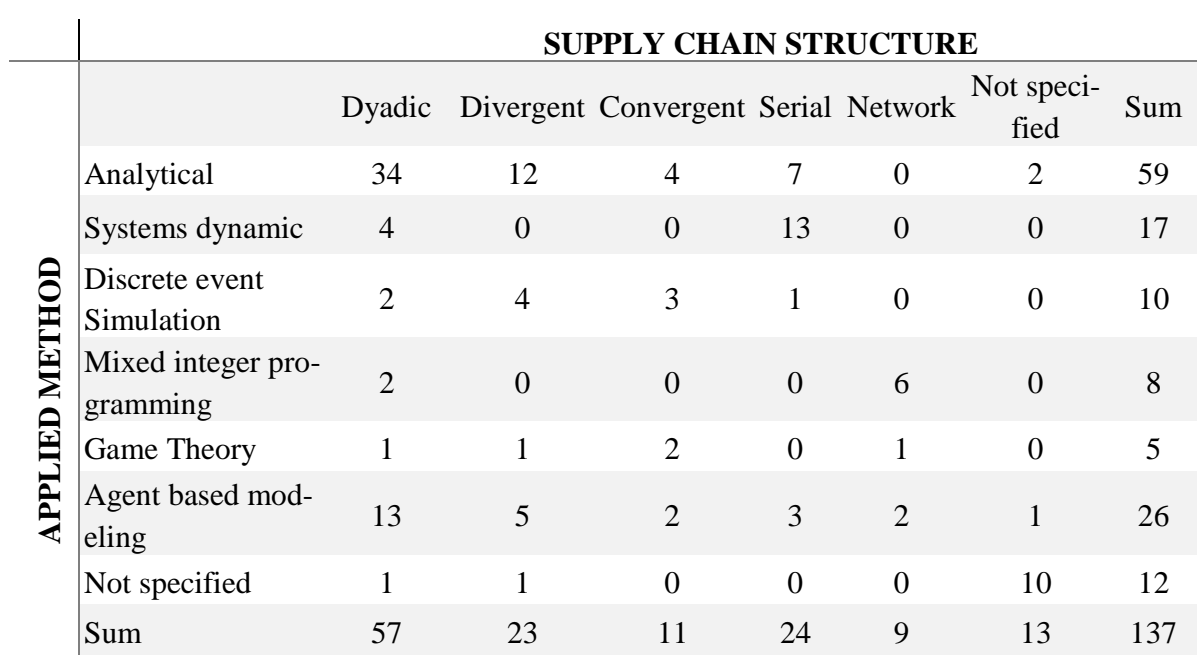

\section{$5 \quad$ Conclusion and Future Research}

This paper contributes to the current body of knowledge on information exchange by explicitly showing and clarifying what previous research that have been conducted and how it has been conducted. First, the exchange of demand information and inventory levels, in order to improve order replenishment decisions, has received the highest amount of attention. Second, a tendency within information exchange is to investigate how downstream information can be exploited upstream [1]. Third, a common approach is to simplify the problem to a dyad supply chain structure and solve it analytically [8] [19]. Fourth, the use of both simulation and empirical studies are argued to be effective but not fully exploited methods. They also holds the power of analyzing the more complex network structure. Fifth, rudimentary issues, as which type of information to exchange and with whom is still unclear, and no well-traveled path exist [3] [13] [16]. Those five points summaries the outcome of the six review papers. However, to further develop the link from information exchange to planning and control and better understand the how it influences three directions for future research are deduced:

Research Design. It was highlighted that especially the network structure has previously been overlooked. Only studying dyad and simple supply chain structures may not provide the complete necessary knowledge [19]. It is expected, that this could be accommodated by using simulations models or using in-depth case studies where before and after situations are evaluated through essential performance measurements. 
Level of Information Exchange. Information exchange can occur at different levels [19] and from the six reviews at least four dimensions defines the level of information exchange a supply chain applies. First, frequency and timeliness; this addresses the issue of how often and how far in advance the information should be exchanged to provide the highest benefit. Second, the information content specifies what type of information to exchange. Third, information detail concerns if information should be exchanged at e.g. SKU level or product family level and if it should be in e.g. monthly, weekly or daily time buckets. Fourth, neighborhood relates to the number of supply chain partners, which should receive and send the information. For future research it could be examined how to actually measure this level of information exchange and provide a generic framework, but also to examine the relationship to different planning and control levels.

Challenges and Benefits. Future research should be concerned with the impact on the supply chain performance and the challenges of implementing it. Some of the challenges of sharing data between individual companies is that it requires a great amount of trust, or willingness, as well as secure technical solutions for smooth connectivity [3]. How can a company safely share detailed forecasts with a supplier, if the supplier also supplies the company's biggest competitors? On the other hand, future research should also give some attention to how the benefit should be measured and distributed between various partners.

This paper present the academic perspectives on information exchange and planning and control. It will be continued with a case study of a network supply chain to examine what type of information there currently is exchanged, if the type of information identified through the six review papers include all types of information relevant to consider, and how the information is linked to the planning and control decisions in the case companies.

\section{References}

1. Choi, H-c. P. (2010) "Information Sharing in Supply Chain Management: A Literature Review on Analytical Research", California Journal of Operations Management, Vol. 8 No. 1, pp. 110-116.

2. Dev, N.K., Caprihan, R., \& Swami, S. (2013), "Strategic positioning of inventory review policies in alternative supply chain networks: an information-sharing paradigm perspective", International Journal of Logistics Research and Applications: A Leading Journal of Supply Chain Management, Vol. 16 No. 1, pp. 14-33.

3. Fawcett, S. E., Wallin, C., Allred, C., \& Magnan, G. (2009), "Supply chain informationsharing: benchmarking a proven path", Benchmarking: An International Journal, Vol. 16 No. 2, pp. 222-246.

4. Ferguson, M. and Ketzenberg, M. (2006) "Information sharing to improve retail product freshness of perishables", Production \& Operations Management, Vol 15 No. 1, pp.57-73

5. Fliedner, G. (2003), “CPFR: an emerging supply chain tool”, Industrial Management \& data systems, Vol. 103 No. 1, pp. 14-21.

6. Forrester, J. (1958), "Industrial dynamics: a major breakthrough for decision makers." Harvard Business Review, Vol. 36 No. 4, pp. 37-66 
7. Giard, V., Sali, M. (2013) "The bullwhip effect in supply chains: a study of contingent and incomplete literature", International Journal of Production Research, Vol. 51 Nol. 13, pp. 3880-3893.

8. Huang, G. Q., Lau, J. S., \& Mak, K. L. (2003), "The impacts of sharing production information on supply chain dynamics: a review of the literature", International Journal of Production Research, Vol. 41 No. 7, pp. 1483-1517.

9. Jacobs, F. R., Berry, W. L., Whybark, D. C., Vollmann T. E., (2011) Manufacturing Planning and Control for Supply Chain Management, $6^{\text {th }}$ edition, McGraw-Hill.

10. Jonsson, P. and Mattsson, S.A. (2003). The implications of fit between planning environments and manufacturing planning and control methods, International Journal of Operations and Production Management, Vol. 23 No. 8, pp. 872-900.

11. Jonsson, P. and Mattson, S.A. (2013), "The value of sharing planning information in supply chains", Journal of Physical Distribution and Logistics Management, Vol. 43 No. 4, pp. 282-299

12. Kaipia, Riikka. "Coordinating material and information flows with supply chain planning, (2009) "The International Journal of Logistics Management, Vol. 20 No. 1 p. 144-162.

13. Kumar, R. S., \& Pugazhendhi, S. (2012), "Information sharing in supply chains: An overview", Procedia Engineering, Vol. 38, pp. 2147-2154.

14. Lee, H. L., Padmanabhan, V., \& Whang, S. (1997), "The bullwhip effect in supply chains", Sloan management review, Vol. 38 No. 3, pp. 93-102.

15. Li, G., Hong, Y., Wang, S. and Xia, Y., (2005) "Comparative analysis on value of information sharing in supply chains", Supply Chain Management, Vol. 10 No. 1, pp. 34-46

16. Moberg, C. R., Cutler, B. D., Gross, A., \& Speh, T. W. (2002). "Identifying antecedents of information exchange within supply chains", International Journal of Physical Distribution \& Logistics Management, Vol. 32 No. 9, pp. 755-770.

17. Montoya-Torres, J. R., \& Ortiz-Vargas, D. A. (2014), "Collaboration and information sharing in dyadic supply chains: A literature review over the period 2000-2012", Estudios Gerenciales, Vol. 30 No. 133, pp. 343-354.

18. Olhager, J., and Rudberg, M., (2002) Linking manufacturing strategy decisions on process choice with manufacturing planning and control systems, International Journal of Production Research, Vol. 40 No. 10, pp. 2335-2351

19. Sahin, F., \& Robinson, E. P. (2002), "Flow coordination and information sharing in supply chains: review, implications, and directions for future research", Decision sciences, Vol. 33 No. 4, pp. 505-536.

20. Thatte, A. A., Rao, S. S., \& Ragu-Nathan, T. S. (2013), "Impact of SCM practices of a firm on supply chain responsiveness and competitive advantage of a firm", Journal of Applied Business Research, Vol. 29 No. 2, pp. 499-530.

21. Yang, Z., and Zhang L. (2013) "Information Sharing in Supply chain: A Review", Journal of Digital Information Management, Vol. 11 No. 2, pp. 125-130

\section{$7 \quad$ Acknowledgements}

This paper is part of the Norwegian research project Retail Supply Chain 2020 funded by the Research Council of Norway and participating industrial companies. The four year project was initiated in 2014 and this paper especially contributes on one of the four key research areas of designing new advanced planning and control models through information exchange. 